\title{
A new family of rhamnogalacturonan lyases contains an enzyme that binds to cellulose
}

\author{
Vincent A. MCKIE ${ }^{\star}$, Jean-Paul VINCKEN $\dagger$, Alphons G. J. VORAGEN $\dagger$, Lambertus A. M. VAN DEN BROEK $\dagger$, Elaine STIMSON $\ddagger$ \\ and Harry J. GILBERT ${ }^{\star 1}$ \\ *Department of Biological and Nutritional Sciences, University of Newcastle upon Tyne, Newcastle upon Tyne NE1 7RU, U.K., †Laboratory of Food Chemistry, \\ Department of Agrotechnology and Food Sciences, Wageningen University, P.0. Box 8129, 6700 EV Wageningen, The Netherlands, and \$DuPont (U.K.) Ltd, \\ 40 Station Road, Cambridge CB1 2UJ, U.K.
}

\begin{abstract}
Pseudomonas cellulosa is an aerobic bacterium that synthesizes an extensive array of modular cellulases and hemicellulases, which have a modular architecture consisting of catalytic domains and distinct non-catalytic carbohydrate-binding modules (CBMs). To investigate whether the main-chain-cleaving pectinases from this bacterium also have a modular structure, a library of $P$. cellulosa genomic DNA, constructed in $\lambda$ ZAPII, was screened for pectinase-encoding sequences. A recombinant phage that attacked arabinan, galactan and rhamnogalacturonan was isolated. The encoded enzyme, designated Rgl11A, had a modular structure comprising an $\mathrm{N}$-terminal domain that exhibited homology to Bacillus and Streptomyces proteins of unknown function, a middle domain that exhibited sequence identity to fibronectin-3 domains, and a C-terminal domain that was homologous to family 2a CBMs. Expression of the three modules of the Pseudomonas protein in Escherichia coli showed that its $\mathrm{C}$-terminal module was a functional cellulose-binding domain, and the N-terminal module consisted of a catalytic domain that hydrolysed rhamnogalacturonan-containing substrates. The activity of Rgl11A against apple- and potato-derived
\end{abstract}

rhamnogalacturonan substrates indicated that the enzyme had a strong preference for rhamnogalacturonans that contained galactose side chains, and which were not esterified. The enzyme had an absolute requirement for calcium, a high optimum $\mathrm{pH}$, and catalysis was associated with an increase in absorbance at $235 \mathrm{~nm}$, indicating that glycosidic bond cleavage was mediated via a $\beta$-elimination mechanism. These data indicate that $\mathrm{Rg} 111 \mathrm{~A}$ is a rhamnogalacturonan lyase and, together with the homologous Bacillus and Streptomyces proteins, comprise a new family of polysaccharide lyases. The presence of a family $2 \mathrm{a}$ CBM in Rgl11A, and in a $P$. cellulosa pectate lyase described in the accompanying paper [Brown, Mallen, Charnock, Davies and Black (2001) Biochem. J. 355, 155-165] suggests that the capacity to bind cellulose plays an important role in the activity of mainchain-cleaving Pseudomonas pectinases, in addition to cellulases and hemicellulases.

Key words: carbohydrate-binding module, polysaccharide lyase family 11 .

\section{INTRODUCTION}

The plant cell wall is a composite macromolecule consisting principally of pectin, hemicellulose and cellulose. Pectins, which are found mainly in the primary cell wall, are the most complex plant structural polysaccharides [1]. They are defined by the presence of a high proportion of galacturonic acid. There are three types of pectic polysaccharide present in primary cell walls; homogalacturonan, rhamnogalacturonan I and rhamnogalacturonan II [2,3]. Homogalacturonan comprises the 'smooth' region of pectin and consists of $\alpha$-1,4-linked D-galactopyranouronic acid residues in which the carboxylic acid group may by methylated [2]. Rhamnogalacturonan II is also composed of a homogalacturonan backbone which is substituted with as many as 20 differently linked glycosyl residues [3]. Regions of rhamnogalacturonan I are often referred to as the 'hairy' regions of pectins. The rhamnogalacturonan I backbone consists of the repeated disaccharide unit...4- $\alpha$-D-galactopyranouronic acid- $\alpha$ 1,2-L-rhamnopyranose-(1,... Approx. $50 \%$ of the rhamnose units are substituted at C-4 with galactan, arabinan and arabinogalactan polymers [2].
There is an extensive repertoire of enzymes that act in synergy to degrade pectin. The main chain of pectin is cleaved by a combination of glycoside hydrolases and polysaccharide lyases. Glycoside hydrolases cleave glycosidic bonds via acid-baseassisted catalysis [4]. In contrast, polysaccharide lyases cleave sugar polymers via a $\beta$-elimination mechanism resulting in the formation of a double bond between C-4 and C-5 at the newly formed non-reducing end [5]. Lyases generally attack glycosidic bonds in which galacturonic acid is the non-reducing sugar, as the hydrogen at C-5 is activated by the electron-withdrawing properties of the C-6 carboxylic acid moiety [6]. In the smooth region of pectins $\alpha-1,4$ glycosidic bonds are cleaved by either lyases or glycoside hydrolases [6]. In contrast, the $\alpha-1,4$ bonds in rhamnogalacturonan I are hydrolysed only by rhamnogalacturonan rhamnohydrolases and rhamnogalacturonan lyases, while the $\alpha-1,2$ linkage is cleaved by either rhamnogalacturonan galacturonohydrolases or rhamnogalacturonan hydrolases [7].

Both glycoside hydrolases and polysaccharide lyases are grouped into enzyme families (see http://afmb.cnrs-mrs.fr/ $\sim$ pedro/CAZY/db.html). Members of the same family are

\footnotetext{
Abbreviations used: CBM, carbohydrate-binding module; CBM2a, family 2a CBM; Fn3, fibronectin type 3 module; HPAEC, high-performance anionexchange chromatography; HPSEC, high-performance size-exclusion chromatography; MHR-S, saponified modified hairy region; Pel10A, pectate lyase 10A; Rgl11A, rhamnogalacturonan lyase 11A; RDA, Red-Dyed Arabinan; GST, glutathione S-transferase; Caps, 3-(cyclohexylamino)propane-1sulphonic acid; ORF, open reading frame; PSP, putative secreted protein.

1 To whom correspondence should be addressed (e-mail H.J.Gilbert@Newcastle.ac.uk).

The nucleotide sequence depicted in Figure 3 has been submitted to the DDBJ, EMBL, GenBank ${ }^{\circledR}$ and GSDB Nucleotide Sequence Databases under the accession number AY026755.
} 
thought to have evolved from a common ancestral sequence and have the same mechanism of action. All the homogalacturonan and rhamnogalacturonan hydrolases are grouped in glycoside hydrolase family 28 , while pectate and pectin lyases are found in five of the ten polysaccharide lyase families.

The majority of glycoside hydrolases that attack the cellulose and hemicellulose components of the plant cell wall are modular enzymes consisting of catalytic modules appended to noncatalytic carbohydrate-binding modules (CBMs [8]). In contrast, the pectinases described to date lack CBMs. It could be argued that these differences in the molecular architectures of plant-cellwall hydrolases reflect the availability of these polymers to enzyme attack. Thus the relatively simple structures of pectinases are due to the accessibility of pectins to soluble biocatalysts. However, it is possible that the non-modular structure of the pectinases described to date is more a reflection of their microbial origins; the majority of these enzymes are not derived from micro-organisms that express a repertoire of CBM-containing plant-cell-wall hydrolases. Thus it is our hypothesis that cellulolytic microbes, which express cellulases and hemicellulase that contain distinct catalytic domains and CBMs, produce pectinases, which have a modular structure. To test this hypothesis we have initiated studies designed to investigate the molecular architecture of pectinases expressed by the bacterium Pseudomonas cellulosa, that produces an extensive array of modular CBM-containing cellulases and hemicellulases. In this report we show that the pseudomonad expresses a novel rhamnogalacturonan lyase that exhibits sequence identity to Bacillus and Streptomyces proteins whose functions have not been identified. The rhamnogalacturonan lyase therefore defines a new family of polysaccharide lyases designated PL11. In addition, the Pseudomonas enzyme is modular, containing a functional family $2 \mathrm{a}$ CBM (CBM2a) module. These data, together with the accompanying paper [9], therefore show that some microbial pectinases contain cellulose-binding domains, and are thus capable of associating with the plant cell wall.

\section{MATERIALS AND METHODS}

\section{Bacterial strains, plasmids and culture conditions}

The Escherichia coli strains used in this study were BL21(DE3):pLysS (Novagen) and XL1-Blue (Stratagene). The bacteriophage employed was $\lambda$ ZAPII (Stratagene). The plasmid vectors used were as follows: pBluescript $\mathrm{SK}^{-}$(Stratagene), pCR-Blunt (Invitrogen), pGEX4T-3 (Amersham Pharmacia Biotech) and pET32c (Novogen). All E. coli strains containing recombinant plasmids were cultured in LB broth supplemented with $50 \mu \mathrm{g} / \mathrm{ml}$ ampicillin or kanamycin, as appropriate. E. coli cells used to propagate bacteriophage were grown on LB broth supplemented with $10 \mathrm{mM} \mathrm{MgSO}_{4}$ and $0.2 \%$ maltose, and were plated out on NZYM top agar $(0.7 \%)$. To screen the library of $P$. cellulosa DNA constructed in $\lambda$ ZAPII, approx. 20000 recombinant phage were plated out on NZYM top agar supplemented with $0.2 \%$ Red-Dyed Arabinan (RDA; Megazyme, Bray, Ireland) at a density of 3 plaques $/ \mathrm{cm}^{2}$. After incubation at $37^{\circ} \mathrm{C}$ for $24 \mathrm{~h}$, the plates were inspected for clear haloes surrounding plaques in a red background. To generate the recombinant proteins encoded by pET- and pGEX-based expression vectors, recombinant strains of $E$. coli BL21(DE3) harbouring pLysS and E. coli XL1-Blue, respectively, were cultured to mid-exponential phase $\left(D_{550} 0.5\right)$ in LB broth containing ampicillin at $30^{\circ} \mathrm{C}$, after which time isopropyl $\beta$-D-thiogalactoside was added to a final concentration of $1 \mathrm{mM}$, and the cultures were incubated for a further $4 \mathrm{~h}$ at $30^{\circ} \mathrm{C}$.

\section{Recombinant DNA techniques}

Standard recombinant DNA techniques such as Southern hybridization, plaque hybridization, bacterial transformation, agarose gel electrophoresis, plasmid DNA preparation, restriction digestion and ligation were as described previously [10]. The nucleotide sequence of DNA was determined using an ABI Prism Ready Reaction DyeDeoxy ${ }^{\circledR}$ Terminator Cycle Sequencing Kit. The sequencing reactions were electrophoresed, and the fluorescent signals emitted by the DNA molecules were detected using an Applied Biosystems 377A Sequencing System. The complete sequence of the DNA was determined using a series of custom-made primers to initiate DNA synthesis. The complete sequence of both strands was determined, and the DNA sequence was analysed using the DNAsis computer program.

\section{Construction of recombinant plasmids}

DNA sequences encoding the $\mathrm{N}$-terminal, middle and $\mathrm{C}$-terminal modules of the Pseudomonas rhamnogalacturonan lyase 11A (Rg111A) were amplified by the PCR using the primer pairs described in Table 1. PCRs were performed using 2 units of the thermostable DNA polymerase Vent ${ }^{\text {"N }}$ (New England Biolabs). The reactions contained $0-4 \mathrm{mM} \mathrm{MgSO}, 1 \times$ Thermopol Reaction Buffer (New England Biolabs), $0.5 \mu \mathrm{M}$ primers and $60 \mathrm{ng}$ of target DNA in a final volume of $100 \mu \mathrm{l}$. The reactions were subject to 20 cycles at the following temperatures: $95^{\circ} \mathrm{C}$ for $1 \mathrm{~min}, 55^{\circ} \mathrm{C}$ for $1 \mathrm{~min}$ and $72^{\circ} \mathrm{C}$ for $2 \mathrm{~min}$. The resultant DNA was cloned into pCR-Blunt and sequenced to ensure that no mutations had occurred during amplification. To clone DNA sequences into pET32c and pGEX-4T, amplified DNA were digested with $N d e \mathrm{I} / B a m \mathrm{HI}$ and BamHI/XhoI, respectively, and ligated into the appropriately restricted expression vectors.

\section{Table 1 Primers used in PCRs to amplify DNA derived from $\mathrm{rg} / 11 \mathrm{~A}$}

The nucleotides in bold contain the appropriate restriction-enzyme site, which was used to clone the respective amplified DNA sequences into the appropriate expression vector. Fn3, fibronectin 3 module.

\begin{tabular}{lcc}
\hline Primer sequence & Region of $r g / 11 A$ amplified & Protein encoded by amplified DNA \\
\hline 5'-CGCCATATGTGGGGTGTAGCGTTCTGCTG-3' & $100-1940$ & Catalytic module \\
5'-CGCGGATCCTCAGCTGCCGGTTGACCGCCATT-3' & & Fn3 \\
5'-CGCCATATGTCATCGGTGGCAGCACCCCAGGTC-3' & $1960-2258$ & CBM2a \\
5'-CGCGGATCCTCACTGGAACTGGTGGCAGCCCCAA-3' & & $2350-2646$ \\
5'-GGATCCGGTAGCTGCAGCTATGTGATCACC-3' & & \\
5'-CTCGAGGGTCACTCAGTTACACACAGACC-3' & &
\end{tabular}




\section{Purification of proteins}

Cell-free extracts of $E$. coli strains, in which the expression of recombinant proteins had been induced with isopropyl $\beta$-Dthiogalactoside, were prepared as described previously [11]. Proteins containing $\mathrm{His}$ tags were purified by $\mathrm{Ni}^{2+}$ affinity chromatography, using a Talon ${ }^{\circledR}$ matrix, as described previously [11]. Proteins fused to glutathione S-transferase (GST) were purified by affinity chromatography using glutathione-Sepharose 4B affinity matrix (Amersham Pharmacia Biotech), as described previously [12]. The purity of enzymes subjected to affinity chromatography was evaluated by SDS/PAGE [13].

\section{Substrates used in enzyme assays}

Dyed substrates, pectic galactan (potato and lupin) and the corresponding substrates treated with arabinofuranosidase, were purchased from Megazyme. Polygalacturonic acid and pectin were from Sigma, as were the aryl glycosides. Apple and lime pectin were a gift from Dr G. W. Black (University of Northumbria at Newcastle, Newcastle upon Tyne, U.K.). Apple modified hairy regions, which were subsequently saponified (MHR-S), were prepared as described previously [14].

\section{Assays}

Protein was measured by the dye-binding method of Sedmak and Grossberg [15] using BSA as the standard. The capacity of recombinant enzymes to release dyed oligosaccharides from RDA, azo-galactan, AZCL-potato galactan, azo-rhamnogalacturonan, azo-cellulose, azo-mannan and azo-xylan (all supplied by Megazyme) were determined as follows: approx. $10 \mu \mathrm{g}$ of enzyme was incubated with $0.5 \mathrm{ml}$ of $50 \mathrm{mM}$ sodium phosphate buffer, $\mathrm{pH} 7.5$, containing $0.2 \%$ of the dyed substrate, for $1 \mathrm{~h}$ at $37^{\circ} \mathrm{C}$. Then 2 vol. of ethanol were then added and, after thorough mixing, the reaction was centrifuged for $5 \mathrm{~min}$ at $13000 \mathrm{~g}$. The colour in the supernatant was measured at $590 \mathrm{~nm}$ for the azo- and AZCL-based substrates and $520 \mathrm{~nm}$ for RDA, and the units of enzyme activity were determined from a standard curve supplied by the manufacturer. To quantify the capacity of enzymes to cleave substrates by a $\beta$-elimination mechanism, the enzyme was incubated with appropriate polysaccharides at a final concentration of $1 \%$ in $20 \mathrm{mM} 3-$ (cyclohexylamino)propane-1-sulphonic acid (Caps) buffer, $\mathrm{pH} 9.5$, containing $1 \mathrm{mM} \mathrm{CaCl}$, and the increase in absorbance at $235 \mathrm{~nm}$ was determined. The amount of product released was assessed assuming that the molar absorption coefficient of $\Delta 4,5$ unsaturated galacturonic acid is $5200 \mathrm{M}^{-1} \cdot \mathrm{cm}^{-1}$ [6].

To evaluate the activity of $\mathrm{Rg} 111 \mathrm{~A}$ at different $\mathrm{pH}$ values, the enzyme was incubated with potato pectic galactan in the following buffers: $\mathrm{pH} 6-7,20 \mathrm{mM}$ sodium phosphate buffer; $\mathrm{pH}$ 7-9, $20 \mathrm{mM}$ Tris/ $\mathrm{HCl}$; $\mathrm{pH}$ 9-10, $20 \mathrm{mM}$ Caps buffer; pH 10-11, $20 \mathrm{mM}$ 3-(cyclohexylamino)-2-hydroxypropane-1sulphonic acid (Capso) buffer. The activity of the enzyme was determined at $235 \mathrm{~nm}$ as described above. To analyse the products released from polysaccharides and oligosaccharides, purified Rgl11A was incubated with appropriate substrates for up to $24 \mathrm{~h}$ in $20 \mathrm{mM}$ Caps buffer, $\mathrm{pH} 9.5$, containing $1 \mathrm{mM} \mathrm{CaCl}_{2}$. At regular time intervals aliquots were removed, boiled for $45 \mathrm{~min}$ to inactivate the enzyme, and then subjected to highperformance size-exclusion chromatography (HPSEC) and high-performance anion-exchange chromatography (HPAEC). HPSEC was performed with a Spectrasystem AS3000 autosampler, P1000 pump (ThermoQuest, San Jose, CA, U.S.A.) and a Shodex RI-71 detector. The system was equipped with three Bio-Gel TSK columns in series (40XL, 30XL and 20XL; BioRad). Elution took place at $30^{\circ} \mathrm{C}$ with $0.2 \mathrm{M} \mathrm{NaNO}_{3}$ at $0.8 \mathrm{ml} / \mathrm{min}$. HPAEC was carried out with a Spectrasystem AS3000 autosampler, P4000 pump (ThermoQuest) and an ED40 electrochemical detector (Dionex, Sunnyvale, CA, U.S.A.). The system was equipped with a Dionex CarboPac PA-1 column. A gradient of sodium acetate in $100 \mathrm{mM} \mathrm{NaOH}$ was used as follows: $0-40 \mathrm{~min}, 100-350 \mathrm{mM}$; $40-45 \mathrm{~min}, 350-1000 \mathrm{mM}$; 45-50 $\mathrm{min}, 1000 \mathrm{mM}$ at $1 \mathrm{ml} / \mathrm{min}$. The capacity of different modules of Rgl11A to bind to soluble polysaccharides was evaluated by affinity gel electrophoresis at a ligand concentration of $0.1 \%$, as described previously [16]. The method of Millward-

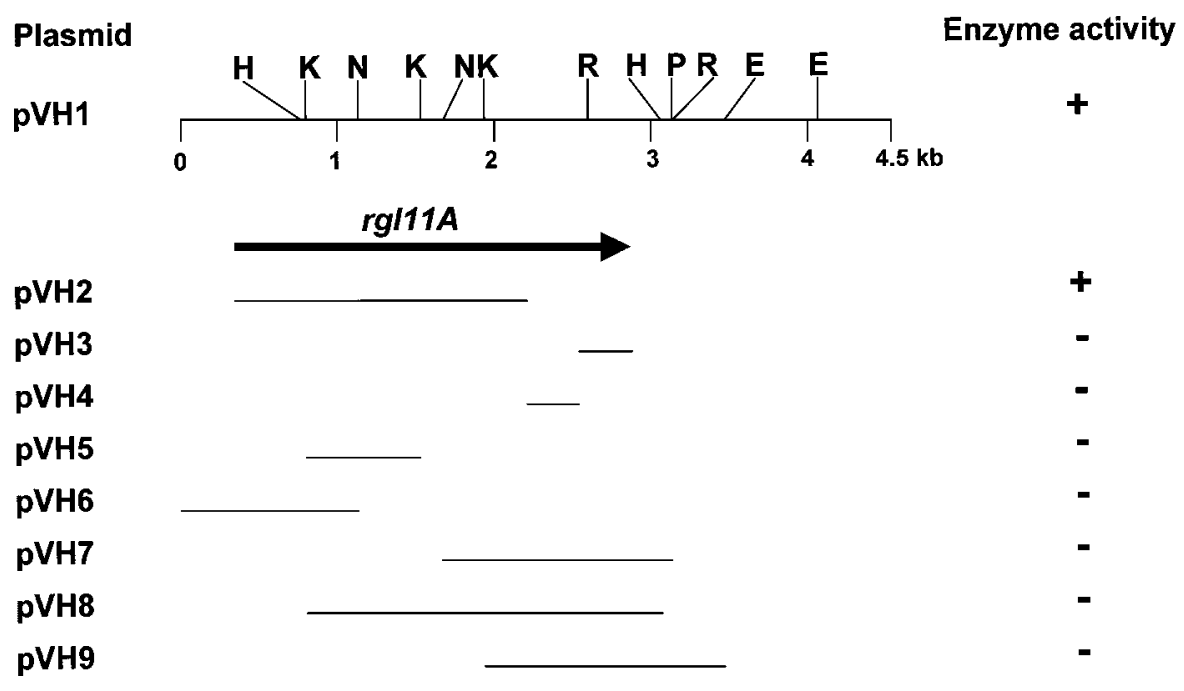

Figure 1 Restriction map of recombinant plasmids containing $\mathrm{rg} / 11 \mathrm{~A}$

The positions of the cleavage sites for the restriction enzymes EcoRl (R), EcoRV (E), Hpal (H), Kpnl (K), Ncol (N) and Pstl (P) are shown. The solid arrow shows the extent and orientation of the rg/11A ORF. The plasmids pVH2-4 were derived from PCRs of pVH1. pVH5-9 were generated by cloning appropriate restriction fragments derived from pVM1 into pBluescript SK- 


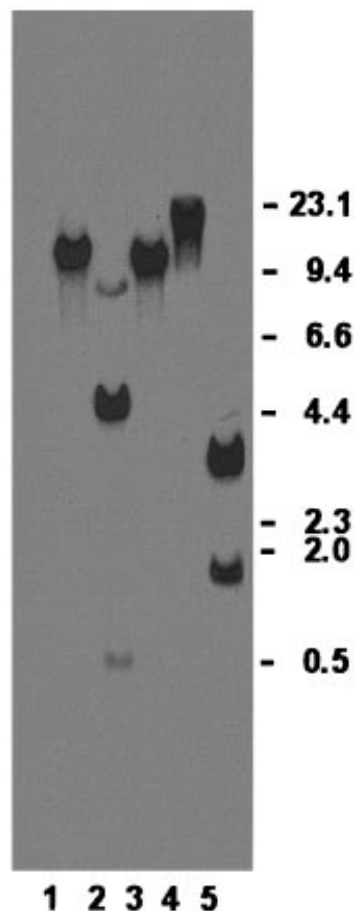

Figure 2 Southern hybridization of $P$. cellulosa genomic DNA using pVH1 as the probe

P. celluosa DNA (5 $\mu \mathrm{g}$ ) was digested with HindIII (lane 1), EcoRI (lane 2), BamHI (lane 3), Xhol (lane 4) and Pstl (lane 5) and subjected to Southern hybridization using the pseudomonad insert in pVH1 as the probe. DNA markers comprising $\lambda$ DNA digested with Hindlll are shown in $\mathrm{kb}$.

Sadler et al. [12] was used to assess the interaction of these modules with insoluble polysaccharides.

\section{RESULTS}

\section{Cloning of $r g / 11 A$}

To isolate $P$. cellulosa genes encoding novel arabinan-degrading enzymes, a genomic library of the bacterium, constructed in $\lambda$ ZAPII, was screened for recombinants that hydrolysed RDA. Out of 20000 phage screened, 11 expressed a functional arabinanase. These recombinant clones could be grouped into two classes based on the degree of RDA cleavage. Group A, comprising six phage, rapidly hydrolysed the substrate, as shown by large clear haloes surrounding the phage in a red background. Group B, consisting of five phage, were surrounded by small diffuse haloes, suggesting that these clones catalyse only limited degradation of arabinan. Cross-hybridization experiments showed that all the group A phage contained the previously characterized $\operatorname{arb} A$ gene encoding a processive endo- $\alpha-1,5-$ arabinanase [17]. To investigate the genetic basis for the slow arabinase-degrading phage (group B), the Pseudomonas insert from one of these clones was excised into the plasmid pBluescript $\mathrm{SK}^{-}$to generate the recombinant plasmid $\mathrm{pVH} 1$. The pseudomonad insert in pVH1 was used to probe all the group B phage. The data (not shown) revealed that all the group B phage crosshybridized to $\mathrm{pVH} 1$. These results indicate that the group $\mathrm{B}$ phage contain a common Pseudomonas DNA sequence, implying that the same arabinanase gene, designated $\operatorname{rglll} \mathrm{A}$, is present in these recombinant clones. A restriction map of the Pseudomonas insert in pVH1 is depicted in Figure 1.
To investigate whether $\operatorname{rg} l 11 \mathrm{~A}$ was a single-copy gene, the pseudomonad insert in pVH1 was used as a probe in the Southern hybridization of $P$. cellulosa genomic DNA. The data (Figure 2) were consistent with the presence of a single copy of rgll1A in the Pseudomonas chromosome.

\section{Sequence of $\mathrm{rg} / 11 \mathrm{~A}$ and its encoded protein}

The sequence of the Pseudomonas insert in pVH1 was determined in both strands. The data, presented in Figure 3, revealed a single open reading frame (ORF) of $2646 \mathrm{bp}$ encoding a protein, designated Rgl11A, of molecular mass 93415 Da. A typical prokaryotic ribosome-binding sequence (AGGAGA) was located $8 \mathrm{bp}$ upstream of the putative translation-initiation codon, and the sequence prior to and immediately after the ORF contains translational stop codons in all three phases. Downstream of the ORF there is an inverted repeat of 14 residues containing a succession of thymine nucleotides characteristic of a Rhoindependent transcription terminator [18]. The codon usage of the ORF is typical of other $P$. cellulosa plant-cell-wall hydrolaseencoding genes [19-21]. To evaluate whether the ORF encoded the arabinan-degrading enzyme, derivatives of $\mathrm{pVH} 1$ in which the ORF had been disrupted were generated, and their capacity to encode a functional polysaccharidase was determined. The data (Figure 1), which showed that plasmids in which the $5^{\prime}$ region of the ORF had been removed did not express a functional arabinan-degrading enzyme, support the view that Rgl11A is encoded by this sequence. The translated sequence of $\mathrm{rg} / 11 \mathrm{~A}$ indicated that Rgl11A has a modular structure comprising three distinct domains separated by classical serine-rich linker sequences present in a range of Pseudomonas plant-cell-wall hydrolases [19-21]. The N-terminus of the protein consists of a typical signal peptide. It contains eight basic residues at the $\mathrm{N}$ terminus, followed by 17 small hydrophobic amino acids capable of forming an $\alpha$-helical structure. Based on the rules of Perlman and Halvorson [22] the cleavage site is predicted to be between amino acids Ala-46 and Ala-47. Downstream of the signal peptide is a module comprising 596 residues which is designated the catalytic domain (CD). Using the BLAST search program the N-terminal module was shown to exhibit extensive sequence identity with the proteins YesW, YesX and a putative secreted protein, PSP (Figure 4A). These polypeptides, which are derived from Bacillus subtilis (YesW and YesX [23]) and Streptomyces coelicolor (PSP [24]), have no known function. The second module of Rgl11A, between residues 656 and 750, exhibits extensive sequence identity with fibronectin type 3 modules (Fn3 [25]; Figure 4B) present in a range of microbial glycoside hydrolases including cellulases and xylanases, and three pectate lyases belonging to PL3. The C-terminal 90-residue module of Rgl11A is homologous to CBM2a cellulose-binding domains. It contains the five tryptophan residues that are completely conserved in other Pseudomonas CBM2a modules, including pectate lyase 10A (Pel10A) described in the accompanying paper [9], three of which (Trp-794, Trp-831 and Trp-848) have been shown to comprise the cellulose-binding surface of these proteins [26,27]. It is interesting to note that the proposed molecular architecture of Rgl11A is similar to the P. cellulosa pectate lyase described in the accompanying paper; this enzyme also contains three modules in which the catalytic domain and the CBM2a are at the $\mathrm{N}$ - and C-termini, respectively [9].

\section{Production of the modules of Rgl11A}

DNA sequences encoding the three modules of Rgl11A were amplified by PCR and cloned into appropriate expression vectors. 
$-90$

GATAAATCTGACTTATATACCCTGTGTTGCGCTTTTTTTGTGCAGTAAAGCGAGTATCCG

$\begin{array}{lllllllllllllllllllll}M & K & I & T & M & Q & G & K & E & P\end{array}$

GCGA.AAAACCCARTAAGGAGATAACTGCCATGAAGATAACCATGCAAGGAAAAGAACCA $+1$

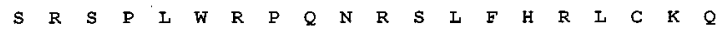
TCGCGGTCGCCACTCTGGCGCCCCCAAAACCGATCACTATT TCATAGGCTATGCAAGCAG

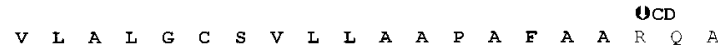
TCCTGGCGCTGGGGTGTAGCGTTCTGCTGGCGGCCCCTGCCTTCGCCGCGCGCCAGGCGG $\begin{array}{llllllllllllllllllll}E & Y & L & D & R & G & V & V & A & L & P & S & G & S & G & I & Y & I & G & W\end{array}$ GAGTATCTGGATCGCGGGGTGGTAGCCCTGCCATCGGGGTCGGGGATTTATATCGGCTGC $\begin{array}{cccccccccccccccccccc}\text { R M } & \text { L } & \text { G } & \text { D } & \text { D } & \text { P } & \text { A } & \text { N } & \text { I } & G & \text { F } & \text { H } & \text { V } & \text { Y } & \text { R } & \text { N } & \text { G } & \text { T } & R \\ \text { CGTATGCTGGGCGATGATCCGGCCAATATCGGCTTCCACGTGTATCGCAATGGCACCCGT }\end{array}$ $\begin{array}{llllllllllllllllllll}I & I & S & S & P & I & T & N & S & T & N & Y & F & D & A & S & G & S & S & S\end{array}$ ATTACGTCAAGTCCGATCACCAATTCCACCAACTACTTCGRTGCCAGT GGCAGCTCCAGT

$\begin{array}{llllllllllllllllllll}A & A & Y & T & V & R & F & V & V & N & G & V & E & Q & A & A & N & F & A & K\end{array}$ GCAGCCTATACOGTGCGCCCGGTTGTGAATGGGGTAGAGCAGGCGGCCAACCCGGCAAAA

$\begin{array}{llllllllllllllllllll}A & T & W & G & N & P & Y & W & L & V & N & I & N & R & P & A & G & G & T & T\end{array}$ GCGACCTGGAGCAACCCCTATTGGCTGGTTAACCTCAACCGCCCGGCCGGCGGTACCACA

P $S$ S G CCCAGT GGCGAAGCCTATAGCTACTCACCCAACGACCT GAGCGTGGGCGACCTCGATGGC $\begin{array}{llllllllllllllllllll}D & G & Q & Y & D & I & I & V & K & W & E & P & S & N & A & K & D & N & S & Q\end{array}$ GACGGCCAATATGACATTATCGTGAAGTGGGAGCCGTCCAATGCCAAGGACAACTCCCA

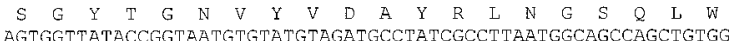
$\begin{array}{llllllllllllllllllll}R & I & D & L & G & R & N & I & R & A & G & A & H & Y & T & Q & F & I & V & Y\end{array}$ CGCATTGACCTCGGCCGTAATATCCGCGCCGGT GCCCACTACACGCAATTTATCGTCTAC

$\begin{array}{llllllllllllllllllll}D & L & D & G & D & G & K & A & E & V & A & M & K & T & A & F & G & T & R & D\end{array}$ GACCTGGACGGTGACGGCAAGGCCGAGGTCGCCATGAAAACAGCCCCCGGTACGCGCGAT

$\begin{array}{llllllllllllllllllll}A & A & G & N & V & L & G & G & S & B & A & N & Y & R & L & R & N & A & S & G\end{array}$ GCAGCGGGTAATGTACTCGGTGGCAGTAATGCCAATTACCGACTCCGCAATGCCAGCGGO

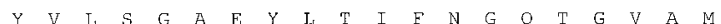
TATGTCCTCTCGGGGGCGGAATACCTGACTATCTTCAATGGCCAGACCGGGGT TGCCATG $\begin{array}{lllllllllllllllllllll}A & T & T & D & Y & V & F & A & R & G & T & V & S & S & W & G & D & N & Y & G\end{array}$ GCAACCACCGACTATGTACCGGCGCGCGGCACGGTCAGCAGTTGGGGCGATAACTATGGC

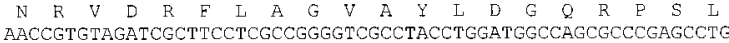
$\begin{array}{llllllllllllllllllll}V & M & A & R & G & Y & Y & T & R & A & V & V & V & A & W & D & W & R & N & G\end{array}$ GTCATGGCGCGCGGT TATTACACCCGTGCAGTGGTGGTTGCCTGGGATTGGCGCAATGGC

$\begin{array}{llllllllllllllllllll}S & L & S & R & R & W & T & E & D & S & N & S & G & G & N & S & A & A & A & G\end{array}$ AGCCTCAGCCGGCGCTGGACGTTCGACAGCAACAGCGGCGGCAACAGCGCGGCAGCCGGC

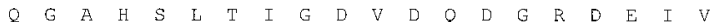
CAGGGCGCCCACTCGCTGACCATTGGCGATGTGGACCAGGACGGCCGCGATGAARTTGTC

Y $G$ A TATGGCGCCGCCACCATCAACGATAACGGTACCCT GCTCTATTCCACCGGCCTGGGGCAT $G \begin{array}{lllllllllllllllllll}G & A & L & H & L & G & D & F & A & P & N & R & P & G & L & E & V & F & M\end{array}$ GGCGATGCCTTGCACCTGGGCGATT TCAACCCCAACCGGCCGGGGCTGGAAGTGTITATG $\begin{array}{lllllllllllllllllllll}V & H & E & S & P & S & S & Y & G & Q & H & G & I & E & M & H & D & A & R & T\end{array}$ GTGCACGAATCCCCTCCAGCTATGGCCAGCACGGTATTGAAATGCACGATGCGCGCACC $\begin{array}{llllllllllllllllllll}G & A & I & V & W & S & V & Q & G & G & G & D & I & G & R & G & V & T & M & D\end{array}$ GGCGCTATCGTCTGGAGTGTACAGGGCGGT GGCGATATAGGTCGCGGGGTAACCATGGAT

$\begin{array}{llllllllllllllllllll}V & D & P & R & Y & F & G & N & E & S & W & A & S & T & G & G & L & Y & S & A\end{array}$ GTCGATCCGCGCTATCCCGGTACGAAAGCTGGGCATCCACCGGCGGACTCTACTCCGCC

$\begin{array}{llllllllllllllllllll}T & G & Q & Q & I & T & T & S & K & P & A & S & I & N & F & G & V & W & W & D\end{array}$ ACCGGGCAGCAGATCACCACCAGCAAACCGGCCAGCATTAACTTTGGGGTGTGGTGGGAT

$\begin{array}{llllllllllllllllllll}A & D & I & L & R & E & O & L & N & N & T & M & I & D & K & \text { W } & N & Y & S & N\end{array}$ GCTGACCTGCTGCGCGAGCAGTTGAACAACACCATGATLGACAAGTGGAACTACAGCAAT

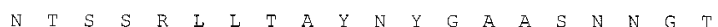
AACACCAGTTCGCGCCTGCTCACAGCCTATAACTACGGTGCGGCGTCCAATAACGGTACC $\begin{array}{llllllllllllllllllll}K & A & T & P & G & L & S & A & D & L & F & G & D & W & R & E & E & V & I & W\end{array}$ AAGGCAACACCGGGGCTATCGGCTGACCTGTTTGGCGACTGGCGCGAAGAAGTGATCTGG $\begin{array}{lllllllllllllllllllll}R & H & D & N & N & S & Q & L & L & I & F & S & T & T & A & V & T & T & H & K\end{array}$ CGCCACGACAACAACAGCCAGTTGCTGATCTTTAGCACCACTGCTGTCACCACCCACAAG

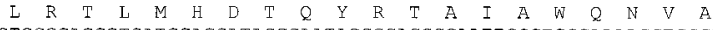
CTGCGCACGCTGATGCACGATACCCAMTACCGCACGGCAATTGCCTGGCAAAACGTGGCT

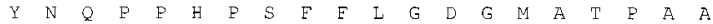
TACAACCAGCCACCCCACCCCAGCTTCTTCCTGGGCGATGGTATGGCGACACCGGCGGCA $\mathrm{DCD}$

P D I Y F V G T N P N G G S T G S S S S CCGGATATTTACTTTGTAGGCACCAACCCCAATGGCGGTTCAACCGGCAGCTCATCGAGC $\boldsymbol{U}_{\mathrm{Fn} 3}$

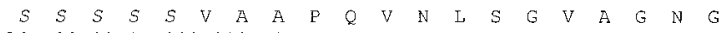
AGTTCCAGCTCATCGGTGGCAGCACCCCAGGTCAACCTGAGCGGTGTGGCCGGTAATGGC

Q V V S S I $S$ S CAGGTCAGTTTGAGTTGGACCGTGAATGGCAGCATTAACGGTATCGAAATCTATCGCGAT

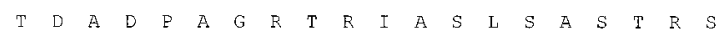
ACCGATGCCGATCCTGCGGGCCGCACGCGCATCGCATCCCTGAGTGCCAGCACGCGCAGC

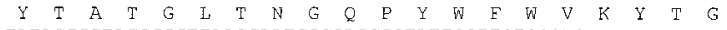
TATACGGCTACCGGGTTAACCAATGGCCAGCCCTATTGG ITCTGGGTGAAATACACCGGG

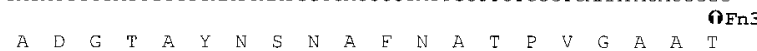
GCAGATGGCACGGCCTACAATTCCAATGCCTTCAACGCAACCCCGGTTGGGGCTGCCACO

$\begin{array}{llllllllllllllllllll}S & S & S & S & S & V & A & S & S & S & S & S & S & S & S & S & S & V & A & S\end{array}$ AGTTCCAGC TCCTCAGTGGCGTCT TCAAGTTCGTCATCCTCTTCCAGCTCCGTGGCCAGC

\section{UCBM2a}

$\begin{array}{lllllllllllllllllllll}S & A & V & S & S & S & S & A & A & S & G & G & S & G & S & C & S & Y & V & I\end{array}$ AGTGCTGTATCCAGTTCCTCGGCGGCCAGTGGCGGCAGCGGTAGCTGCAGCTATGTGATC

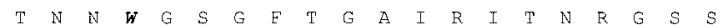
ACCAATAACTGGGGCTCCGGTTTTACCGGTGCGATTCGCATCACCAATCGCGGCAGCAGO

$\begin{array}{llllllllllllllllllll}A & I & N & G & W & N & V & S & W & T & Y & S & G & N & T & R & I & S & N & S\end{array}$ GCGATTAACGGTTGGAATGTCAGCTGGACCTACAGCGGTAATACCCGCATTAGCAATAGC

$\begin{array}{llllllllllllllllllll}W & N & A & T & \text { V } & S & G & S & N & P & Y & S & A & A & N & L & G & W & N & A\end{array}$ TGGAATGCCACTGTCAGCGGCAGCAATCCCTACAGCGCTGCCAACCTGGGCTGGAATGCA $\begin{array}{llllllllllllllllllll}T & I & Q & P & G & Q & T & V & E & E & G & F & Q & G & T & Y & S & G & S & T\end{array}$ ACCATCCAGCCGGGGCAAACCGTGGAATTCGGTTTCCAGGGGACTTACTCCGGCAGCACC E $\quad$ T DCBM2a

GAAACGCCCGTGATCAGTGGGTCTGTGTGTAACTGAGTGACCAAAAGAAAAAGGGGCAGT

CATGCCCCTTTITCTTGCT TCTTGCGCTAAATATTTCCGGCAATGGTITAGTGTTCACCC

\section{Figure 3 Nucleotide sequence of $r g / 11 A$ and the deduced primary structure} of Rgl11A

The nucleotide sequence of $r g / 11 A$ and the primary structure of Rgl11A are shown. The putative signal peptide is in bold, the linker sequences are in italics and the inverted repeated sequence at the $3^{\prime}$ end of the gene is identified by arrows. The conserved tryptophans in the CBM2a are depicted as bold and italicized letters. The start and end of each module is indicated by $\downarrow$ and $\uparrow$, respectively, over the appropriate amino acid, followed by the name of the module [catalytic domain (CD), Fn3 and CBM2a].

The region encoding the $\mathrm{N}$-terminus and the Fn3 homologue were cloned into pET32C, thus the encoded modules contained thioredoxin and a $\mathrm{His}_{6}$ tag, whereas the sequence encoding the CBM2a homologue was inserted into pGEX4T-3 and thus the encoded protein contained GST fused to its N-terminus. The recombinant proteins containing the His tags were purified by $\mathrm{Ni}^{2+}$ affinity chromatography, whereas the GST-CBM2a fusion protein was purifed by affinity chromatography using glutathione-Sepharaose $4 \mathrm{~B}$ as the matrix. The purified proteins were subjected to SDS/PAGE, and the data are presented in Figure 5.

\section{Biochemical characterization of the Fn3 and CBM2a homologues in Rgl11A}

Polysaccharide-binding experiments showed that the C-terminal CBM2a homologue of Rgl11A bound to bacterial microcrystalline cellulose (Figure 6), but did not interact with insoluble xylan or mannan. When the module was denatured by treating with $2 \%$ SDS or $6 \mathrm{M}$ guanidine hydrochloride, it did not interact with cellulose, demonstrating that the protein only binds to the polysaccharide when it folds into a three-dimensional structure (results not shown). These data show that the $\mathrm{C}$-terminal module of Rgl11A comprises a typical CBM2a cellulose-binding domain. Analysis of the biochemical properties of the Fn3 homologue showed that the module did not exhibit catalytic activity against, or bind to, apple and lime pectin, potato and lupin pectic 
A

Rgl11A

031526

031527

086724

RglilA

031526

031527

08672

Rgl11A

031526

031527

086724

Rgl11A

031526

031527

086724

Rgl11A

031526

031527

086724

RglilA

031526

031527

086724

Rgl11A

031526

031527

086724

Rgl11A

031526

031527

086724

Rgl11A

031526

031527

086724

Rgl11A

031526

031527

086724

$\mathrm{Rg} 111 \mathrm{~A}$

031526

031527

086724

B

Rgl11A

Q47465

Q47471

050325

Rgl11A

Q47465

Q47471

050325

---MKITMQGKEPSRSPLWRPQNRSLFHRICKQVLALGCSVLLAAPAFAARQAEYLDRGV 57 -...--.-MRRSCLMIRRRKRMFTAVTLLVLLVMGTSVCPVKAEGAAROMEALNRGL 49 - MRHPHTRPHAPHPHRRRPRALAAALAAAGLLGAGLTTLAFDTAEAATARQVEALDRGV 58

VALPSGSGIYIGWRMLGDDPANIGFHVYRNGTRITSSPITNSTNYFDASGSSSAAYTVRP 1 I VAVKTDGGI FVSWRFLGTENASVLFNVYRDGQKLNAAPVKTTN-YVDKNGSAGSTYTVRA 108 IAVQTEQGVFVSWRFLGTDHETTAFHIYRDGKRITRDPIAESTNELDQNGTADSVYQVAA 75 VSVHTGDGNLVSWRWLGTDPDNVAENVYRAGTKVNSSPVTGSTTYEHSGAPSHADYTVRA 118

$$
* * * * * \text { * } * * * * *
$$

VVNGVEOAANPAKATWSNPYWLVNLNRPAGGTTPSGEAYSYSPNDLSVGDLDGDGOYDI I 177 VVNGTEOPASEKASVWAOPYHSVPLDKPAGGTTPKGESYTYSANDASVGDVDGDGOYETI 168 VNKGREEKLSKKARVWQENVLEVPLAKPEGGVTPDGKPYTYSANDASVGDIDGDGEYEMI 135 VVNGTEQGDSVHAIQFRAGYKDVPISPPSGGTTPDGVSYTYEANDASVGDLDGDGALDLV 178

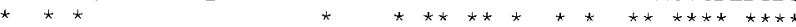

VKWEPSNAKDNSQSGYTGNVYVDAYRLNGSQLWRIDLGRNIRAGAHYTQFIVYDIDGDGK 237 LKWDPSNSKDNSQDGYTGDVLIDAYKLDGTKLWRINLGKNIRAGAHYTQFMVYDIDGDGK 228 LKWDPSNSKDNAHDGYTGEVLIDAYKLDGTFLWRINLGRNIRAGAHYTQFMVYDI_DGDGK 195 LKWQPTNAKDNSQSGYTGNTVVDGIKLDGTRLWRVDLGRNIRSGAHYTQEQVYDYDGDGR 238

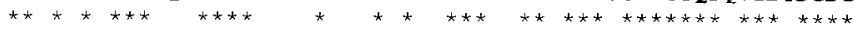

AEVAMKTAPGTRDAAGNVLGGSNANYRLRNASGYVLSGAEYLTIFNGQTGVAMATTDYVP 297 AEVAMKTADGTKDGTGKVIGNANADYRNE--QGRVLSGPEYLTVFQGSTGKELVTANEEP 286 AEIAMKTADGTTDGKGHIIGDEQADERNE--QGRILSGPEYLTVFKGETGEALTTVEYEP 253 AEVAMKTADGTKDGTGAVIGNSSADHRNS--SGYVLSGPEYLTMFNGRTGTZMGTVDYVP 296

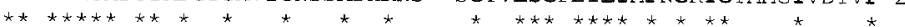

ARGTVSSWGDNYGNRVDRELAGVAYLDGQRPSLVMARGYYTRAVVVAWDWRNGSISRRWT 357 ARGNVSDWGDSYGNRVDRFLAGIAYLDGORPSLIMTRGYYAKTMLVAYNFRDGKL SKLWT 346 PRGKLEDWGDGYGNRMDRELAGTAYLDGERPSLVMARGYYTRTVLVAYDFRNGRLKKRWV 313 ARGSVSSWGDSYGNRVDRFLAGTAYLDGSRPSVIMARGYYTRTVIAAWDWRDGRFTRRWT 356 $* * \quad * * * * * * * * * * * * * * * * * * * * * * * * *$ ******

FDSNSGGNS--AAAGQGAHSLT IGDVDQDGRDE IVYGAATINDNGTLLYSTGLGHGDALH 415 LDSSKSGNE--AFAGQGNHNLS I ADVDGDGKDEIIFGSMAVDHDGKGMYSTGLGHGDALH 404 FDSNQPGHE--AYAGQGNHSLSVADVDGDGKDE I I YGAMAVDHDGTGLYSTGLGHGDAMH 371 FDTNSSTNSGKGYDGQGNHQL SVADVDGDGRDE IVYGAMAVDDNGYALWTTRNGHGDAMH 416

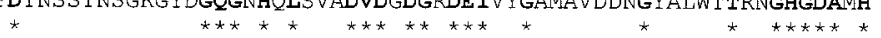

LGDENPNRPGLEVEMVHESPSSYGQHGIEMHDARTGAIVWSVOGGGDIGRGVTMDVDPRY 475 TGDLDPGRPGLEVFOVHEDKN--AKYGLSERDAATGKILWGVYAGKDVGRGMAADIDPRY 462 VGDLDPSRKGLEVFOVHEDAT--KFYGLSLRDAGTGEILWGVHAGTDVGRGMAAHIDPSY 429 VGDLDPSRAGLEEFKVDEDGS---KPSSYLADARTGQILWSTGASGDNGRGVSGDIWSGS 473

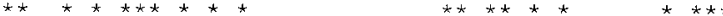

PGNESWASTG-------GLYSATGQQITTSKPASINFGVWWDADLLREQLNN------- 520 PGQEVWANG--------SLYSAKGVKIGSGVPS STEGIWWDGDLLREOIDS------N 507 KGSLVWGIDPPGNDGMSYGLFTSKGEKISDKAPS SANFA IWWDGDLVREILLDHDWDGTIG 489 AGAESWSSAES-------GIRNPKGTVVGSRKPSSANFLSWWDGDTVRELLDG------ 519

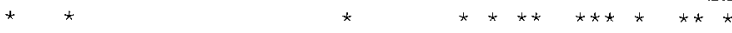

-TMIDKWNYSNNTSSRLLTAYNYGAASNNGTKATPGLSADLFGDWREEVIWRHDNNSOLL 579 R--IDKWDYQNGVSKNMLTAS--GAAANNGTKATPTLQADLLGDWREEVVWRTEDSSALR 563 RPKIEKWDAENGCLKTI EQPA--GVLSNNGTKGNPVIQQANL FGDWREEVIWRTEDSSALR 547 ---THVDKYGTSGDTRLLTGS--GVASNNGTKAT PVLAGDILGDWREEVWWRT SNNTALR 574

$$
\star * \star * * * * * \quad * \star * \star * * * * * \text { * }
$$

IFSTTAVTTHKLRTLMHDTOYRTA IAWONVAYNOPPHPSFFLGDGMATPAAPDIYFVGTN 639 IYTTTIPTEHRLYTLMHDPVYRLGIAWONIAYNOPPHTSFFLGDGMAEOPKPNMYTP--- 620 IYTTTHLTRHCEYTLMHDPVYRLGIAWQNTAYNQPPHTSFYLGTGMKKPPKPALYIAGSK 607 IYSTPYDTDTRITTLJHDTOYRTALAWQNTAYNQPPHPSFFLGSGMPTAPRPSVHTP -. - 631

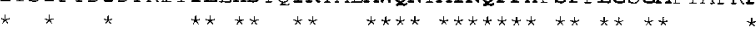

SVAAPOVNLSGVAGNGOVSLSWTVNGSINGIEIYRDTDADPAGRTRIASISASTRSYTAT 60 QAQADDTMLMLLKKDNATYLSWSTDGNVVRQDVYRSTSSAQAGSEKIAELNSSDRTETDL 60 QAQADDTMLMLLKKDNATYLSWSTDGNVVRQDVYRSTSNNQAGSEKIAELNSTDRTETDL 60 ESEAAQTTLMLSQKSDVNYLGWSTDESVARQEVYRGTTSNPDLRERIAVLDAETRTEKDA 60

GLTNGQPYWFWVKYTGADGTAYNSNAFNATPVGAATSS 98 TANPOSDYWYWVDTVSGNNSVLKSNAASTAPAPLRAAP 98 TANPKSDYWYWVDTVSSNNNVQKSNAAQTAPAPLRAAP 98 DTNSGLNYWYWVDVVSENQAQVVSNAVNAGPLRAAKAS 98

$$
* \star \star * * * * *
$$

\section{Figure 4 Comparison of the catalytic and fibronectin modules of Rgl11A with other proteins in the SWISS-PROT database}

The catalytic module (residues 48-644; $\mathbf{A}$ ) and the Fn3 (residues 657-747; B) were compared with sequences in the SWISS-PROT database. Residues that are identical in all sequences compared are in bold and are indicated with *. The accession numbers refer to the following proteins. (A) 031526, YesX from B. subtilis [23]; 031527, YesW from B. subtilis [23]; 086724, PSP from S. coelicolor [24]. (B) Q47465 and Q47471 are PL3 pectate Iyases from Erwinia carotovora [35,36]; 050325 is a PL3 pectate Iyase from Erwinia chrysanthemi [37]. 

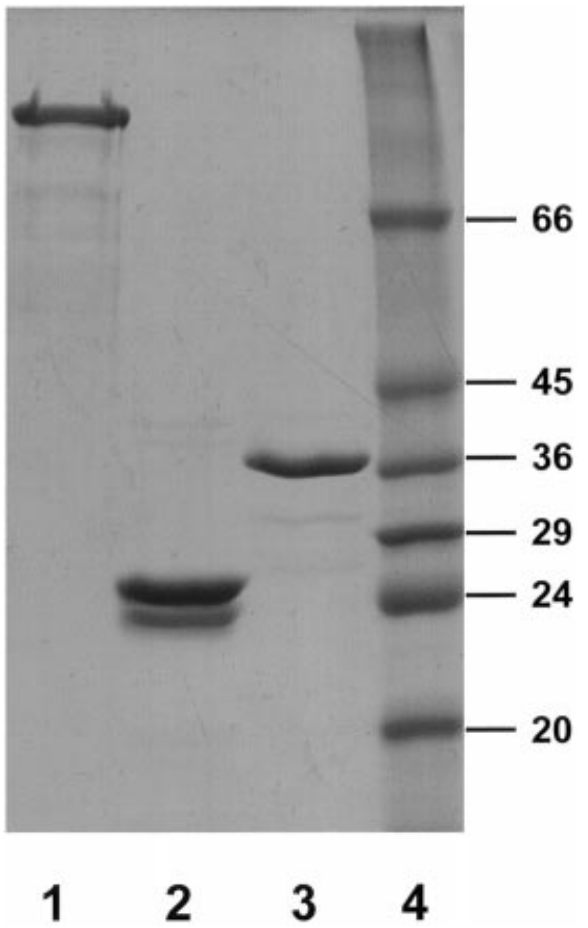

\section{Figure 5 Purified modules of Rgl11A}

The catalytic module fused to thioredoxin and a $\mathrm{His}_{6}$ tag (lane 1), the Fn3 fused to thioredoxin and a $\mathrm{His}_{6}$ tag (lane 2) and the CBM2a cellulose-binding domain fused to GST (lane 3) of Rgl11A were purified by either $\mathrm{Ni}^{2+}$ affinity chromatography (catalytic module and $\mathrm{Fn3}$ ) or glutathione-Sepharose affinity chromatography (CBM2a), as described in the Materials and methods section, and subjected to SDS/PAGE using a $10 \%$ (w/v) polyacrylamide gel. The sizes, in $\mathrm{kDa}$, of protein molecular-mass markers are shown in lane 4.

galactan, sugar beet arabinan, polygalacturonic acid, rhamnogalacturonan, hydroxyethyl, carboxymethyl, acid-swollen and bacterial microcrystalline forms of cellulose, ivory nut mannan, carob galactomannan, arabinoxylan from rye or wheat and oat spelt xylan (results not shown). Thus the function of Fn3, in common with its counterparts in other glycoside hydrolases, remains to be elucidated.

\section{Catalytic activity of the N-terminal region of Rgl11A}

The capacity of the N-terminal module of Rgl11A to degrade a range of dyed polysaccharides was evaluated. The data (Table 2) showed that the protein released dyed oligosaccharides from RDA, azo- and AZCL-galactan and azo-rhamnogalacturonan, but exhibited no activity against dyed forms of cellulose, mannan or xylan. These data indicate that Rgl11A cleaves glycosidic bonds in the galactan, sugar beet arabinan and rhamnogalacturonan polysaccharides. It is probable, therefore, that the enzyme cleaves the rhamnogalacturonan backbone that is present in all these substrates. Cleavage of glycosidic bonds in which the aglycone sugar is galacturonic acid can be by acid-base-assisted catalysis, which is mediated by glycoside hydrolases [4], or via a $\beta$-elimination, which is catalysed by pectin lyases, pectate lyases and rhamnogalacturonan lyases [6]. The latter mechanism generates an unsaturated sugar which exhibits a maximum absorbance at approx. $235 \mathrm{~nm}$ [6]. To evaluate the mechanism of action of Rgl11A, the enzyme was incubated with potato pectic

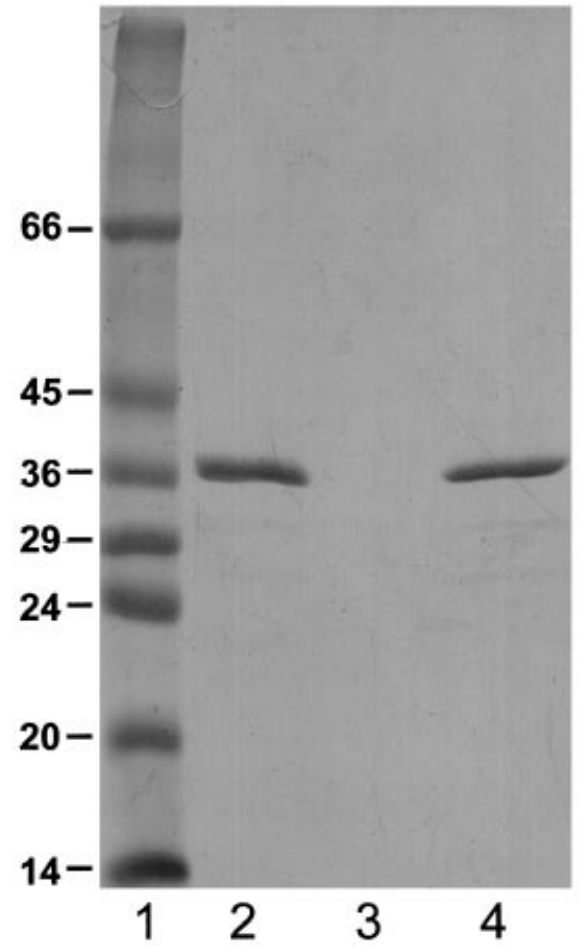

\section{Figure 6 Binding of the CBM2a of Rgl11A to cellulose}

The CBM2a of Rgl11A fused to GST (lane 2) was incubated with bacterial microcrystalline cellulose at $25^{\circ} \mathrm{C}$ for $1 \mathrm{~h}$ and, after removing unbound protein (lane 3 ), the polysaccharide was washed repeatedly in $50 \mathrm{mM}$ sodium phosphate buffer, $\mathrm{pH}$ 7.0, and bound protein was eluted by boiling for $5 \mathrm{~min}$ in $10 \%$ SDS (lane 4). The various fractions were subjected to SDS/PAGE using a $10 \%(\mathrm{w} / \mathrm{v})$ polyacrylamide gel. The sizes, in $\mathrm{kDa}$, of protein molecular-mass markers are shown in lane 1 .

\section{Table 2 Activity of Rgl11A against dyed polysaccharides}

Rgl11A activity was detected by the release of soluble dyed oligosaccharides as described in the Materials and methods section. One unit of enzyme activity releases $1 \mu \mathrm{mol}$ of dye $/ \mathrm{min}$. NA, no activity detected.

Substrate $\quad$ Rgl11A activity (units/mg of protein)

\section{Azo-potato galactan}

AZCL-potato galactan

Azo-rhamnogalacturonan

RDA

Azo-carboxymethylcellulose

Azo-carob galactomannan

Azo-oat spelt xylan

22
14
8
3
NA
NA
NA

galactan and the UV spectrum of the reaction was determined. The results, presented in Figure 7, showed that as the reaction progressed the absorbance spectrum revealed a distinct peak at $235 \mathrm{~nm}$, strongly indicating that the enzyme cleaves the rhamnogalacturonan backbone via a lyase mechanism.

To investigate the biochemical properties of Rgl11A in more detail, the capacity of the enzyme to cleave a range of substrates was evaluated. The data, presented in Table 3, showed that the enzyme hydrolysed apple and lime rhamnogalacturonan, potato and lupin pectic galactan. No activity against polygalacturonic 

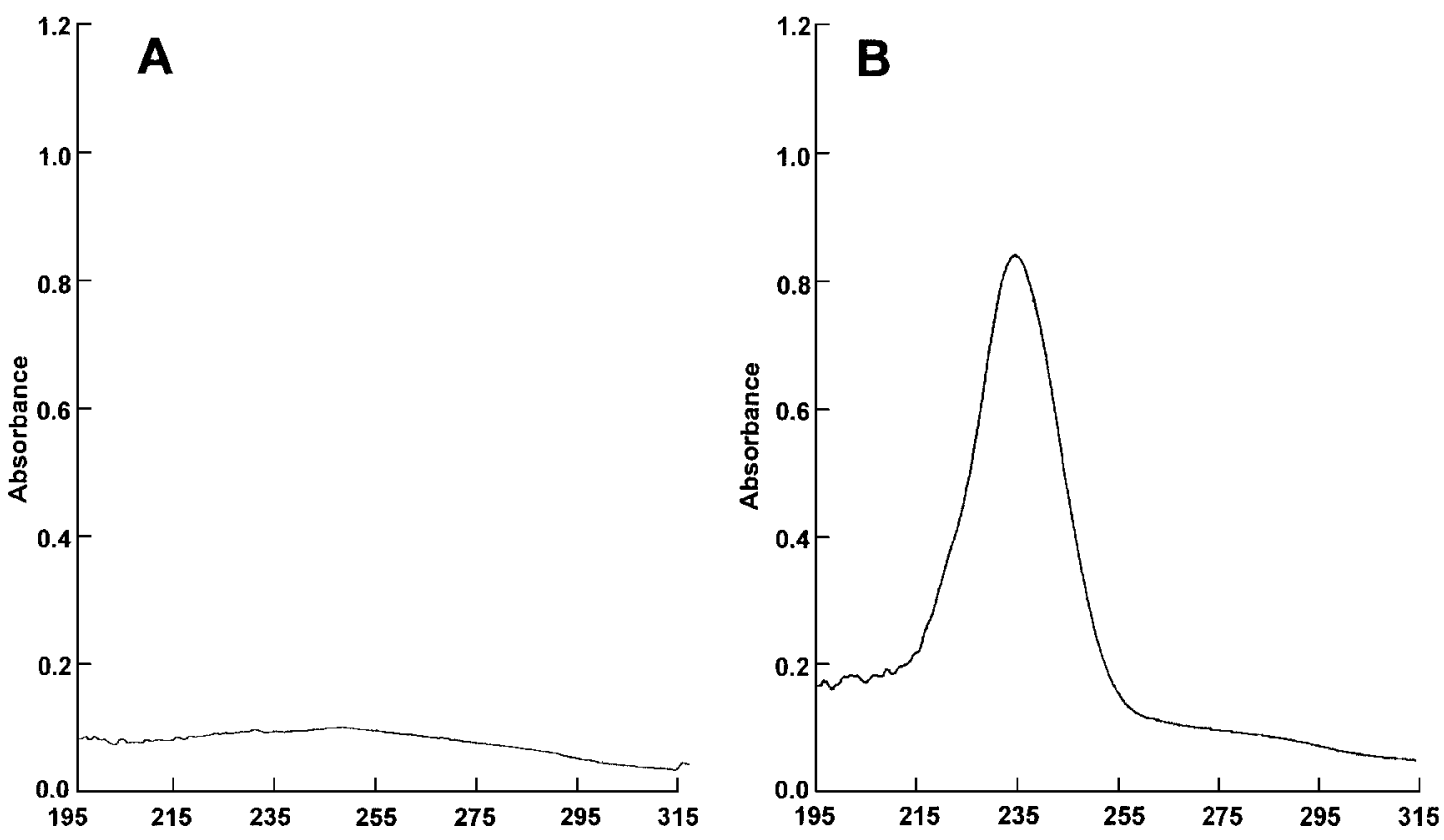

Figure 7 UV scan of the products generated by Rgl11A

Rgl11A (10 $\mu \mathrm{g})$ was incubated with $1 \%(\mathrm{w} / \mathrm{v})$ potato galactan pectin in $20 \mathrm{mM}$ Caps buffer, pH 9.5, containing $1 \mathrm{mM} \mathrm{CaCl} 2$ for $2 \mathrm{~h}$ at $37^{\circ} \mathrm{C}$. The UV absorbance of the reaction immediately after the addition of enzyme and after a $2 \mathrm{~h}$ incubation are shown in $(\mathbf{A})$ and $(\mathbf{B})$, respectively.

\section{Table 3 Catalytic activity of Rgl11A against different pectins}

The catalytic activity of Rgl11A was assayed against the pectic substrates by measuring the increase in $A_{235}$ in $20 \mathrm{mM}$ Caps buffer, $\mathrm{pH} 9.5$, containing $1 \mathrm{mM} \mathrm{CaCl}$, using a substrate concentration of $1 \%$. The activity was relative to potato pectic galactan, whose activity was designated as 1 . The kinetic parameters were determined by measuring the increase in $A_{235}$ in $20 \mathrm{mM}$ Caps buffer, $\mathrm{pH} 9.5$, containing $1 \mathrm{mM} \mathrm{CaCl}$. A dash signifies that the kinetic parameters were not determined. ND, no activity detected.

\begin{tabular}{llll}
\hline Substrate & Catalytic activity & $k_{\text {cat }}\left(\mathrm{s}^{-1}\right)$ & $K_{\mathrm{m}}(\mathrm{mg} / \mathrm{ml})$ \\
\hline Potato pectic galactan & 1 & 6500 & 8.5 \\
Apple modified hairy regions & 0.05 & - & - \\
Saponified lime pectin & 0.51 & - & - \\
Lupin pectin galactan & 0.23 & - & - \\
Apple MHR-S & 0.65 & - & - \\
Polygalacturonic acid & ND & - & - \\
\hline
\end{tabular}

acid was detected. These data support the view that Rgl11A is a rhamnogalacturan-specific lyase that exhibits no activity against polygalacturonic acid. This is in sharp contrast with Pel10A, described in the accompanying paper, which appears to be a classic polygalacturonan lyase, as its primary substrate is polygalacturonic acid [9].

\section{The reaction products generated by $\mathrm{Rg} / 11 \mathrm{~A}$}

Rgl11A was incubated with MHR-S from apple, and the degradation of MHR-S was monitored by HPLC analysis. The HPSEC traces (Figure 8A) clearly show a reduction in molecular mass with time. After an initial decrease in the size of the polymer, intermediate size products ( 29 min elution time) start to accumulate after $4 \mathrm{~h}$. After $24 \mathrm{~h}$ small oligosaccharides (32 min elution time) are also present. The HPAEC profiles in Figure
8(B) confirm these results; at $4 \mathrm{~h}$ small oligosaccharides start to appear, and these products steadily increase during further incubation. These results are consistent with an endo mode of action of Rgl11A.

To probe the importance of side chains in the substrate recognition of Rgl11A, the action of the enzyme against apple rhamnogalacturonan oligosaccharides was also assessed using HPAEC. The enzyme cleaved an oligosaccharide comprising a backbone of $R_{1}-G_{1}-R_{2}-G a_{2}-R_{3}-G_{3}$, where $R$ is a rhamnose and Ga galacturonic acid, in which $\mathrm{R}_{1}$ and $\mathrm{R}_{3}$ have galactose moieties attached. However, the enzyme did not attack the oligosaccharide degalactosylated with a $\beta$-galactosidase (results not shown). These data indicate that Rgl11A is an endo-acting rhamnogalacturonan lyase that cleaves derivatives of this substrate which are de-esterified but contain galactose side chains.

\section{Biophysical properties of Rgl11A}

The activity of the purified N-terminal region of Rgl11A was evaluated in a range of different conditions. The $\mathrm{pH}$-activity profile of the lyase showed that the enzyme had a $\mathrm{pH}$ optimum of 9.5 (Figure 9A). Typical of most $P$. cellulosa polysaccharidases, $\mathrm{Rg} 111 \mathrm{~A}$ retained catalytic activity up to a temperature of $55^{\circ} \mathrm{C}$, after which it was rapidly inactivated (Figure 9B). The majority of alkali-acting lyases described to date have an absolute requirement for calcium. To evaluate the importance of the bivalent metal ion in the activity of Rgl11A, the enzyme was treated with $10 \mathrm{mM}$ EDTA and then extensively dialysed against $50 \mathrm{mM}$ sodium phosphate buffer, $\mathrm{pH}$ 7.0. The enzyme did not cleave potato pectic galactan; however, Rgl11A exhibited catalytic activity when calcium was added to the reaction at a final concentration of $1 \mathrm{mM}$. No activity was detected when magnesium, manganese or zinc was added to Rgl11A instead of 

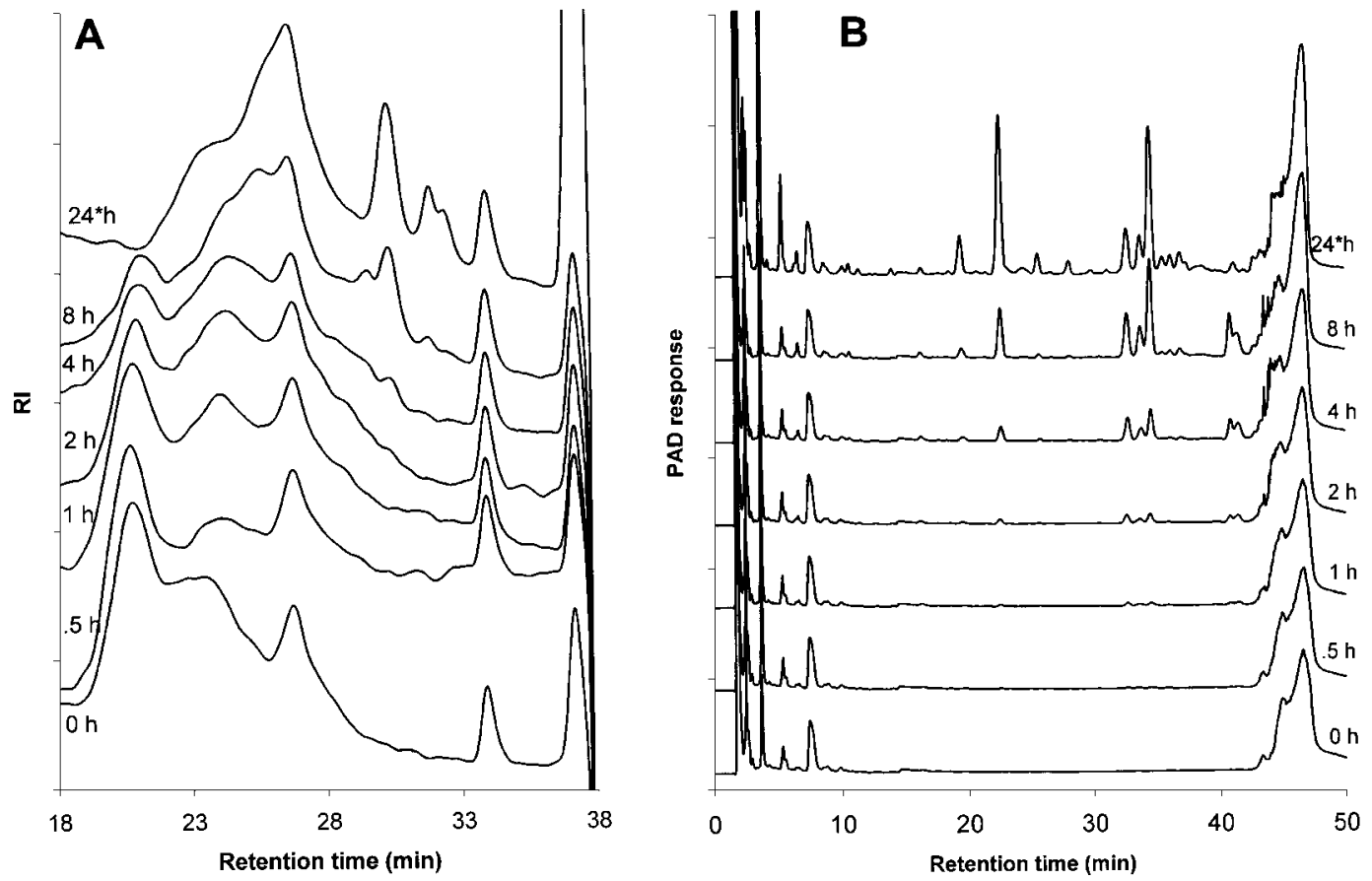

Figure 8 Analysis of the products released from MHR-S by Rgl11A

Rgl11A was incubated with MHR-S as described in the Materials and methods section. At regular time intervals an aliquot was removed, boiled for 30 min to inactivate the enzyme, and subjected to HPSEC (A) and HPAEC (B). PAD, pulsed amperometric detector; Rl, refractive index. 24*h indicates approx. $24 \mathrm{~h}$.

calcium (Table 4). Rgl11A, in common with the majority of extracellular plant-cell-wall-degrading enzymes expressed by the pseudomonad, was completely resistant to proteinase attack (results not shown).

\section{DISCUSSION}

The data described in this paper and in the accompanying paper [9] demonstrate for the first time that $P$. cellulosa expresses enzymes that attack pectin. Rgl11A exhibits specificity for substituted rhamnogalacturonans. In Nature the rhamnogalacturonan component of pectin is highly substituted with galactan and arabinan side chains [2]. The hydrolysis of the backbone component of the polysaccharide would open up the pectin structure, making it more accessible to enzyme attack. Thus an enzyme such as Rgl11A that exhibits specificity towards substituted rhamnogalacturonans is likely to play a pivotal role in the initial degradation of hairy pectin.

$P$. cellulosa, in common with other plant-cell-wall-degrading micro-organisms, contains extensive multigene families encoding cellulases and hemicellulases [28,29]. It is surprising, therefore, that only a single rhamnogalacturonan lyase and pectate lyase [9] were isolated from the Pseudomonas gene library, particularly as plant pathogenic prokaryotes, such as Erwinia, contain extensive multigene families encoding polygalacturonases, pectate lyases and pectin lyases (see http://afmb.cnrs-mrs.fr/ $\sim$ pedro/CAZY/db.html). In addition, our screening strategy did not identify DNA sequences encoding other main-chaincleaving pectinases such as polygalacturonases or rhamnogalacturonan hydrolases. These data suggest that pectin is not a primary target of the pseudomonad, a view supported by the observation that the bacterium does not use galacturonic acid or rhamnose as a carbon source (results not shown). It is possible that the role of the $P$. cellulosa pectinases is to 'loosen' the matrix pectins in the primary cell wall, making the cellulose and hemicellulose polysaccharides, which are the main targets for this bacterium, more accessible to enzyme attack. However, the conclusion that the pseudomonad does not contain multigenefamily-encoded pectinases, or contains the full range of pectinolytic enzymes, must be viewed with some caution. It is possible that our screens, and that of Brown et al. in the accompanying paper [9], failed to identify all the main-chain pectinases in the pseudomonad genome. For example, some of the pectinases may not have attacked the dyed substrates, the pectinase genes are not expressed in E. coli, or the polysaccharidase genes are not represented in the gene library, as they are lethal to the enteric bacterium. This last possibility is consistent with the observation that the high-level expression of several $P$. cellulosa glycoside hydrolases is lethal to $E$. coli, due to inefficient secretion $[17,30,31]$.

To date there are 10 families of polysaccharide lyases, of which only family 4 contains rhamnogalacturonan lyases (see http://afmb.cnrs-mrs.fr/ pedro/CAZY/db.html). The catalytic module of Rgl11A exhibits no homology to polysaccharide lyase family 4 , but exhibits extensive sequence identity with three proteins from B. subtilis and $S$. coelicolor, of unknown function. These data indicate strongly that Rgl11A and the Streptomyces and Bacillus polypeptides have evolved from a common ancestral sequence. We propose, therefore, that Rgl11A, YesW, YesX and PSP comprise a new polysaccharide lyase family which, according to the classification of $\mathrm{B}$. Henrissat and P. M. Coutinho (see http://afmb.cnrs-mrs.fr/ pedro/CAZY/db.html), is designated PL11. To date, enzymes belonging to the same family of glycoside hydrolases and polysaccharide lyases have a common mechanism of action, and thus it is highly likely that the Bacillus 

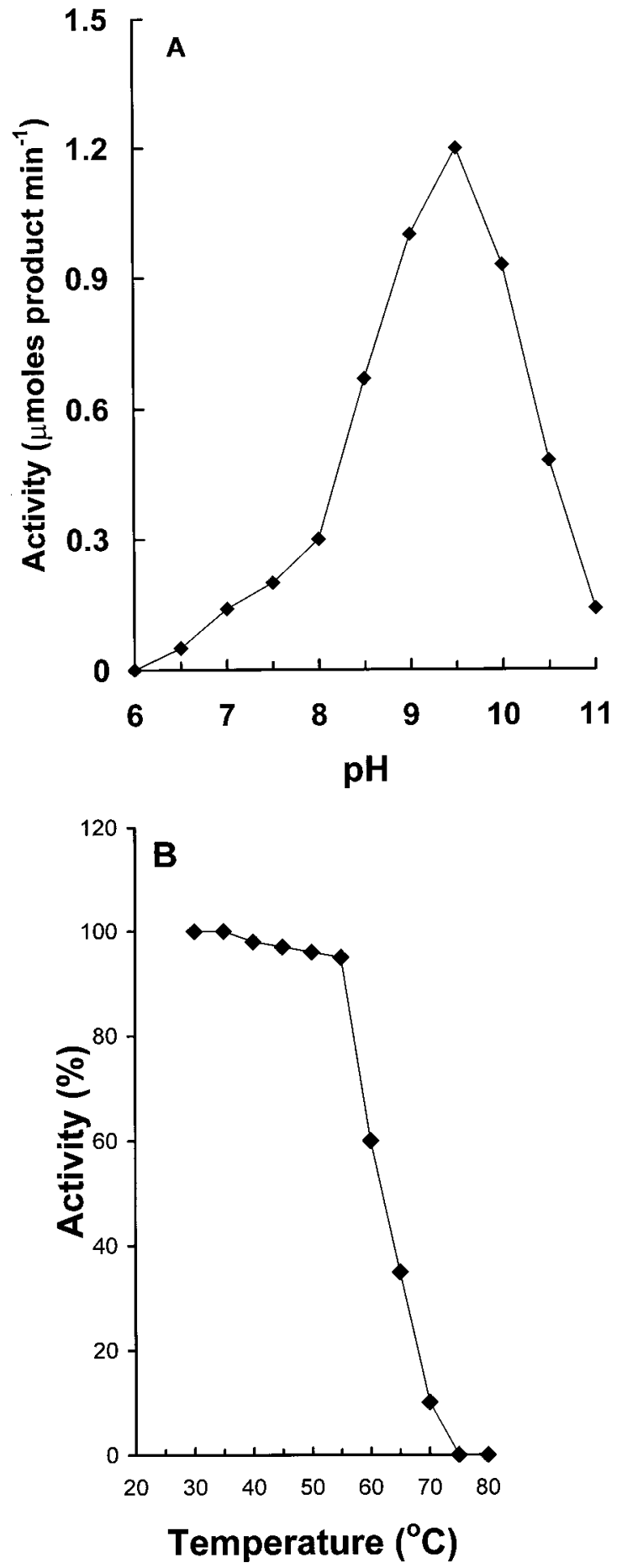

Figure 9 Biophysical properties of Rgl11A

(A) The activity of Rgl11A was assayed at the different $\mathrm{pH}$ values indicated by measuring the increase in $A_{235}$ using potato pectic galactan as the substrate. The buffers used in each reaction are described in the Materials and methods section. (B) The temperature stability of Rgl11A was evaluated by incubating the enzyme at various different temperatures for $10 \mathrm{~min}$, placing the enzyme on ice and then assaying for residual lyase activity at $37^{\circ} \mathrm{C}$.

and Streptomyces proteins are also rhamnogalacturonan lyases. However, it remains to be established whether YesW, YesX and PSP, in common with Rgl11A, are also rhamnogalacturonan lyases, which exhibit specificity towards substrates substituted
Table 4 The influence of metal ions on the activity of Rgl11A

Rgl11A was treated with $10 \mathrm{mM}$ EDTA, and then dialysed extensively against $50 \mathrm{mM}$ sodium phosphate buffer, $\mathrm{pH} 7.0$. The activity of the enzyme was then determined using $0.2 \%$ potato pectic galactan as the substrate in $20 \mathrm{mM}$ Caps buffer, $\mathrm{pH}$ 9.5. Metal ions were added to a final concentration of $1 \mathrm{mM}$.

\begin{tabular}{lll}
\hline Enzyme treatment & Metal ion added & Relative activity \\
\hline Calcium $(1 \mathrm{mM})$ & - & 1.0 \\
No treatment & - & 0.2 \\
EDTA & - & 0.0 \\
EDTA & Calcium & 0.9 \\
EDTA & Magnesium & 0.0 \\
EDTA & Manganese & 0.0 \\
EDTA & Zinc & 0.0 \\
& & \\
\hline
\end{tabular}

with galactose moieties. Support for the view that YesW and YesX attack rhamnogalacturonan can be inferred from the chromosome location of their respective genes. They are adjacent, in the Bacillus chromosome, to a gene encoding YesY, a rhamnogalacturonan acetyl esterase [23], and as closely linked prokaryotic genes often encode proteins of related function, it is likely that YesW and YesX are rhamnogalacturonan lyases. In this context it is interesting to note that adjacent to the genes encoding YesW and YesX is a gene that codes for YesZ, which comprises a $\beta$-galactosidase. This could imply that the two Bacillus lyases only hydrolyse deacetylated and degalactosylated rhamnogalacturonan. The lack of a $\beta$-galactosidase gene in close vicinity to $\operatorname{rgll1A}$ is consistent with the capacity of Rgl11A to cleave substrates with $\beta$-linked galactose side chains.

Rgl11A, and Pel10A described in the accompanying paper [9], provide the first example of prokaryotic pectinases that contain a CBM. It has been suggested that CBMs play a pivotal role in the activity of enzymes that attack highly recalcitrant polysaccharides within the plant cell wall; typically cellulose and xylan [19-21,28,32]. CBMs, by attaching to their target ligands bring their respective enzymes into close proximity with the target substrates, increasing the efficiency of catalysis [11,33,34]. It is generally believed that pectins are more accessible to enzyme attack than cellulose and hemicelluose; thus there has been no evolutionary pressure for pectinases to contain CBMs. However, Rgl11A only attacks pectins that have been saponified, and thus the rhamnogalacturonan lyase acts in synergy with other enzymes to cleave its target polysaccharide. The presence of a CBM2a cellulose-binding domain in P. cellulosa Rgl11A and Pel10A [9] would enable these enzymes to assemble on the plant cell wall and thus potentiate the synergy between these biocatalysts. In contrast with the rhamnogalacturonan and pectate lyases from P. cellulosa, the other 100 microbial pectinases, both lyases and glycoside hydrolases (see http://afmb.cnrs-mrs.fr/ pedro/ CAZY/db.html), described to date do not contain CBMs. The evolutionary rationale for the prevalence of cellulose-binding domains in Pseudomonas pectinases, but not in the corresponding enzymes from a wide range of micro-organisms, both eukaryotic and prokaryotic, is not readily apparent.

To conclude, Rgl11A is a rhamnogalacturonan lyase, and its homology to products of Streptomyces and Bacillus ORFs indicates that these proteins comprise a novel pectate lyase family designated PL11. This report also shows that Rgl11A, and the Pel10A described in the accompanying paper [9], contain typical CBM2as. It would appear, therefore, that the capacity to bind cellulose is not restricted to cellulases and hemicellulases, but can be extended to backbone-cleaving pectinases. 


\section{REFERENCES}

1 Carpita, N. C. and Gibeaut, D. M. (1993) Structural models of primary cell walls in flowering plants: consistency of molecular structure with the physical properties of the walls during growth. Plant J. 3, 1-30

2 Thakur, B. R., Singh, R. K. and Handa, A. K. (1997) Chemistry and uses of pectin - a review. Crit. Rev. Food Sci. Nutr. 37, 47-73

3 Darvill, A. G., McNeil, M. and Albersheim, P. (1978) Structure of plant cell walls. VIII. A new pectic polysaccharide. Plant Physiol. 62, 418-422

4 Koshland, D. E. (1953) Stereochemistry and the mechanism of enzymatic reactions. Biol. Rev. Camb. Philos. Soc. 28, 416-436

5 Moran, F. S., Nasuno, S. and Starr, M. P. (1968) Extracellular and intracellular polygalacturonic acid trans eliminase of Erwinia carotovora. Arch. Biocem. Biophys. 123, 298-306

6 Jurnak, F., Kita, N., Garrett, M., Heffron, S. E., Scavetta, R., Boyd, C. and Keen, N. (1996) Functional implications of the three-dimensional structures of pectate lyases. In Pectin and Pectinases (Visser, J. and Voragen, A. G. J., eds.), pp. 295-307, Elsevier, Amsterdam

7 Mutter, M., Beldman, G., Pitson, S. M., Schols, H. A. and Voragen, A. G. J. (1998) Rhamnogalacturonan $\alpha$-D-galactopyranosyluronohydrolase - An enzyme that specifically removes the terminal non-reducing galacturonosyl residues in rhamnogalacturonan regions of pectin. Plant Physiol. 117, 153-163

8 Warren, R. A. J. (1996) Microbial hydrolysis of polysaccharides. Annu. Rev. Microbiol. 50, 183-212

9 Brown, I. E., Mallen, M. H., Charnock, S. J., Davies, G. J. and Black, G. W. (2001) Pectate lyase $10 \mathrm{~A}$ from Pseudomonas cellulosa is a modular enzyme containing a family 2a carbohydrate-binding module. Biochem. J. 355, 155-165

10 Sambrook, J., Fritsch, E. F. and Maniatis, T. (1989) Molecular Cloning: a Laboratory Manual, Cold Spring Harbor Press, Cold Spring Harbor

11 Bolam, D. N., Ciruela, A., McQueen-Mason, S., Simpson, P. and Williamson, M. P. (1998) Pseudomonas cellulose-binding domains mediate their effects by increasing enzyme substrate proximity. Biochem. J. 331, 775-781

12 Millward-Sadler, S. J., Poole, D. M., Henrissat, B., Hazlewood, G. P., Clarke, J. H. and Gilbert, H. J. (1994) Evidence for a general role for high-affinity non-catalytic cellulose-binding domains in microbial plant cell wall hydrolases. Mol. Microbiol. 11, 375-382

13 Laemmli, U. K. (1970) Cleavage of structural proteins during the assembly of the head of bacteriophage T4. Nature (London) 227, 680-685

14 Schols, H. A., Posthumus, M. A. and Voragen, A. G. J. (1990) Structural features of hairy regions of pectins isolated from apple juice produced by the liquefaction process. Carbohydr. Res. 206, 117-129

15 Sedmak, J. J. and Grossberg, J. R. (1977) A rapid sensitive and versatile assay for protein using Coomassie Brillant Blue G250. Anal. Biochem. 79, 544-552

16 Simpson, P., Bolam, D. N., Hazlewood, G. P., Gilbert, H. J. and Willamson, M. P. (1999) NMR structure of a Type Ilb xylan binding domain. Structure 7, 853-864

17 McKie, V. A., Black, G. W., Millward-Sadler, S. J., Hazlewood, G. P., Laurie, J. I. and Gilbert, H. J. (1997) Arabinanase A from Pseudomonas fluorescens subsp. cellulosa exhibits both an endo- and an exo- mode of action. Biochem. J. 323, $547-555$

18 Platt, T. (1986) Transcription termination and the regulation of gene expression. Annu. Rev. Biochem. 55, 339-372

19 Hall, J. and Gilbert, H. J. (1988) The nucleotide sequence of a carboxymethylcellulase from Pseudomonas fluorescens subsp. cellulosa. Mol. Gen. Genet. 213, 112-117

20 Gilbert, H. J., Hall, J., Hazlewood, G. P. and Ferreira, L. M. A. (1990) The N-terminal region of an endoglucanase from Pseudomonas fluorescens subspecies cellulosa constitutes a cellulose-binding domain that is distinct from the catalytic centre. Mol. Microbiol. 4, 759-767

21 Kellet, L. E., Poole, D. M., Ferreira, L. M. A., Durrant, A. J., Hazlewood, G. P. and Gilbert, H. J. (1990) Xylanase B and an arabinofuranosidase from Pseudomonas fluorescens subsp. cellulosa contain identical cellulose-binding domains and are encoded by adjacent genes. Biochem. J. 272, 369-376
22 Perlman, D. and Halvorson, H. O. (1983) A putative signal peptidase recognition site and sequence in eukaryotic and prokaryotic signal peptides. J. Mol. Biol. 167, 391-409

23 Kunst, F., Ogasawara, N., Moszer, I., Albertini, A. M., Alloni, G., Azevedo, V., Bertero, M. G., Bessieres, P., Bolotin, A., Borchert, S. et al. (1997) The complete genome sequence of the Gram-positive bacterium Bacillus subtilis. Nature (London) $\mathbf{3 9 0}$, 249-256

24 Redenbach, M., Kieser, H. M., Denapaite, D., Eichner, A., Cullum, J., Kinashi, H. and Hopwood, D. A. (1996) A set of ordered cosmids and detailed genetic and physical map of the $8 \mathrm{Mb}$ Streptomyces coelicolor A3 (2) chromosome. Mol. Microbiol. 21, $77-96$

25 Little, E., Bork, P. and Doolittle, R. F. (1994) Tracing the spread of fibronectin type III domains in bacterial glycohydrolases. J. Mol. Evol. 39, 631-643

26 Nagy, T., Simpson, P., Williamson, M. P., Hazlewood, G. P., Gilbert, H. J. and Orosz, L. (1998) All three surface tryptophans in type Ila cellulose binding domains play a pivotal role in binding both soluble and insoluble ligands. FEBS Lett. $\mathbf{4 2 9}$ 312-316

27 Din, N., Forsythe, I. J., Burtnick, L. J., Gilkes, N. R., Miller, R. C., Warren, R. A. J. and Kilburn, D. G. (1994) The cellulose binding domain of endoglucanase A (CenA) from Cellulomonas fimi: evidence for the involvement of tryptophan residues in binding. Mol. Microbiol. 11, 747-755

28 Millward-Sadler, S. J., Davidson, K., Hazlewood, G. P., Black, G. W. and Gilbert, H. J. (1995) Novel cellulose-binding domains, NodB homologues and conserved molecular architecture on xylanases from the aerobic soil bacteria Pseudomonas fluorescens subspecies cellulosa and Cellvibrio mixtus. Biochem. J. 312, 39-48

29 Hazlewood, G. P. and Gilbert, H. J. (1998) Structure and functional analysis of Pseudomonas plant cell wall hydrolases. Progr. Nucleic Acid Mol. Biol. Res. 61, 211-241

30 Braithwaite, K. L., Barna, T., Spurway, T. D., Charnock, S. J., Black, G. W., Hughes, N., Lakey, J. H., Virden, R., Hazlewood, G. P., Henrissat, B. and Gilbert, H. J. (1997) Evidence that galactanase A from Pseudomonas fluorescens subspecies cellulosa is a retaining family 53 glycosyl hydrolase in which E161 and E270 are the catalytic residues. Biochemistry 36, 15489-15500

31 Bolam, D. N., Hughes, N., Virden, R., Lakey, J. H., Hazlewood, G. P., Henrissat, B. and Gilbert, H. J. (1996) Mannanase A from Pseudomonas fluorescens subsp. cellulosa is a retaining glycosyl hydrolase in which E212 and E320 are the putative catalytic residues. Biochemistry 35, 16195-16204

32 Ferreira, L. M. A., Durrant, A. J., Hall, J., Hazlewood, G. P. and Gilbert, H. J. (1990) Spatial separation of protein domains is not necessary for catalytic activity or substrate binding in a xylanase. Biochem. J. 269, 261-264

33 Gill, J., Rixon, J. E., Bolam, D. N., McQueen-Mason, S., Simpson, P. J., Willamson, M. P., Hazlewood, G. P. and Gilbert, H. J. (1999) The type II and X cellulose-binding domains of Pseudomonas xylanase A potentiate catalytic activity against complex substrates by a common mechanism. Biochem. J. 342, 473-480

34 Black, G. W., Rixon, J. E., Clarke, J. H., Hazlewood, G. P., Theodorou, M. K. and Gilbert, H. J. (1996) Evidence that linker sequences and cellulose-binding domains enhance the activity of hemicellulases against complex substrates. Biochem. J. $\mathbf{3 1 9}$ $515-520$

35 Heikinheimo, R., Flego, D., Pirhonen, M., Karlsson, M. B., Eriksson, A., Mae, A., Koiv, V. and Palva, E. T. (1995) Characterization of a novel pectate lyase from Erwinia carotovora subsp. carotovora. Mol. Plant. Microbe Interact. 8, 207-217

36 Liu, Y., Chatterjee, A. and Charterjee, A. K. (1994) Nucleotide sequence and expression of a novel pectate lyase (pel-3) and a closely linked endopolygalacturonase gene (peh-1) of Erwinia carotovora subsp. carotovora 71 Appl. Environ. Microbiol. 60, 2545-2552

37 Shevchik, V., Robert-Baudouy, J. and Hugouvieux-Cotte-Pattat, N. (1997) Pectate lyase Pell of Erwinia chrysanthemi 3937 belongs to a new family. J. Bacteriol. 179 $7321-7330$

Received 13 July 2000/22 November 2000; accepted 12 January 2001 